\title{
Health outcomes of maternal smoking during pregnancy and postpartum period for the mother and infant: protocol for an umbrella review
}

Tuba Saygın Avşar *iD, Hugh McLeod and Louise Jackson

\begin{abstract}
Background: Internationally, tobacco smoking is a leading cause of mortality, morbidity and health inequality. In England, despite increasing awareness about importance of public health interventions to reduce smoking, about $10 \%$ of pregnant women are known to be smokers at the time of delivery. There are many systematic reviews investigating the impact of maternal smoking during pregnancy on particular health conditions. Hence, this overview of systematic reviews, which aims to include all health conditions for mother and infant caused by smoking during pregnancy, is timely.

Methods: CINAHL, EMBASE, MEDLINE, PsycINFO, Web of Science, CRD Database (includes DARE, NHSEED and HTA) and HMIC databases will be searched for systematic reviews investigating the effects of smoking during pregnancy. Only reviews written in English and published by 31/12/17 will be included. Studies focussed on low-income countries will be excluded. Study selection and quality assessment will be completed by two reviewers independently. To assess the quality of included studies, the Centre for Reviews and Dissemination checklist for systematic reviews will be utilised.

Discussion: Existing systematic reviews focus on the impact of smoking during pregnancy on a specific health condition. This review aims to analyse current evidence on the overall health outcomes associated with smoking whilst pregnant by providing an overview of evidence from systematic reviews.
\end{abstract}

Systematic review registration: PROSPERO CRD42018086350.

Keywords: Smoking during pregnancy, Health outcomes, Overview of reviews, Umbrella review, Systematic review

\section{Introduction}

\section{Background}

Smoking is the highest preventable cause of numerous health problems worldwide [1]. Seven million people die every year because of smoking in the world and more than $18 \%$ of adults smoke daily in OECD countries [2]. In England, 16\% of all deaths were attributed to smoking in 2015 [3]. Smoking during pregnancy is responsible for many avoidable health conditions and deaths across the countries [4]. Smoking status at delivery was $10.5 \%$ in

\footnotetext{
*Correspondence: txs602@bham.ac.uk

Health Economics Unit, Institute of Applied Health Research, College of Medical and Dental Sciences, University of Birmingham, Edgbaston,

Birmingham B15 2TT, UK

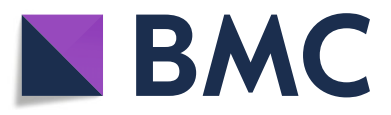

(c) The Author(s). 2018 Open Access This article is distributed under the terms of the Creative Commons Attribution 4.0 International License (http://creativecommons.org/licenses/by/4.0/), which permits unrestricted use, distribution, and reproduction in any medium, provided you give appropriate credit to the original author(s) and the source, provide a link to the Creative Commons license, and indicate if changes were made. The Creative Commons Public Domain Dedication waiver (http://creativecommons.org/publicdomain/zero/1.0/) applies to the data made available in this article, unless otherwise stated. seeking to review evidence across the range of health
} the NHS was up to $£ 87$ million in $2010[5,6]$.

Smoking is the leading cause of inequalities in health across and within countries [7], and there is a negative correlation between education and income levels and smoking [8]. In line with this, the smoking status of pregnant women at the time of delivery is higher in deprived areas of England, being 27\% in Blackpool compared to $2 \%$ in Central London [5].

There are many systematic reviews investigating the impact of maternal smoking during pregnancy on individual health conditions, but there have been few studies 
conditions caused by maternal smoking during pregnancy. In 2010, Godfrey et al. [6] reported a scoping review of the health outcomes associated with smoking during pregnancy. However, their strategy focused on search terms for a limited number of smoking-related health conditions which meant that the review may not have captured some relevant health conditions. In addition, quality assessment of the included studies and reviews was not conducted. Several narrative reviews have surveyed short- and long-term effects of maternal smoking during pregnancy and lactation and presented evidence around the topic $[9,10]$. Nevertheless, these reviews did not systematically assess all available evidence, instead mostly focussed on the negative health effects of nicotine exposure reported in some studies. Considering the large number of published systematic reviews of observational studies regarding the impact of maternal smoking during pregnancy on different health outcomes, an overall evaluation of the current evidence is timely.

\section{Objective of the review}

This review seeks to investigate the impact of smoking during pregnancy and the postpartum period on health outcomes for the mother and infant in developed country settings to inform future research and health policy.

\section{Methods/design}

This umbrella review is designed in line with the objectives and guideline provided by Cochrane Handbook for Systematic Reviews of Interventions [11].

\section{Inclusion criteria}

Studies will be included based on the following eligibility criteria.

\section{Population}

Smoking behaviour, tobacco regulations, access to care for pregnant women, and other related factors are different in high- and middle-income countries compared to low-income countries, and consequently, health outcomes of smoking during pregnancy may not be the same [12-17]. For this reason, systematic reviews of studies focussing on low-income countries will be excluded [18]. There will not be any exclusions based on age or social groups.

\section{Intervention/effect}

This review will focus on the health impacts of maternal smoking during pregnancy and the postpartum period. Therefore, studies that investigated the effect of maternal smoking during pregnancy and postpartum period will be included.

\section{Comparator}

The comparator is defined as pregnant or postpartum women who have never smoked or who have quit smoking.

\section{Outcome measure}

The primary outcome measures for this review are the health outcomes of smoking during pregnancy and the postpartum period for the mother and infant. Outcomes include pregnancy-related clinical problems and longterm adverse health outcomes for the infant. Measures may include odds ratios and relative risks for smoking women and their children compared to non-smoking women and their children.

\section{Study design}

Only systematic reviews published in a peer-reviewed journal will be included in the review.

\section{Language}

For pragmatic reasons, this review will only include systematic reviews written in English.

\section{Publication date}

This study will include systematic reviews published up to 31 December 2017.

\section{Search strategy}

A scoping search was conducted using MEDLINE with the words "pregnant women", "pregnant smokers", "maternal smoking", "health outcomes", "cost outcomes", and "QALYs". Then, the InterTASC Information Specialists Sub-Groups (ISSG) filter was used to identify keywords. Additionally, the keywords of five systematic reviews in relevant topics were reviewed. Identified keywords were discussed with two experts to crosscheck. The chosen search terms are shown in Additional file 1: Appendix 1.

The literature search strategy of this review is defined as follows:

1- The selected keywords within each concept will be combined with "OR", and concepts will be combined with "AND".

2- The inclusion criteria will be piloted by the reviewers independently in order to maximise the consistency of the study selection process.

3- CINAHL, EMBASE, MEDLINE, PsycINFO, Web of Science, CRD Database (includes DARE, NHSEED and HTA) and HMIC databases will be searched with those identified keywords. In addition, references of selected studies will be searched for relevant articles. 
4- The phase of screening for eligibility will be conducted by two reviewers independently. Any discrepancies will be resolved by discussion with a third reviewer.

\section{Data extraction}

A data extraction sheet was created which covers the lead author's name and publication year, study design and the databases searched, number of studies included, main outcomes, and some other methodological information (Additional file 1: Appendix 2). The extraction tool will be piloted. One reviewer (TS) will extract the data and another reviewer (HM) will check the extracted data to minimise any bias.

\section{Data management}

Data management will be done by using ENDNOTE and Microsoft Excel software.

\section{Quality assessment}

The Centre for Reviews and Dissemination's practical checklist for conducting a critical appraisal of systematic reviews was modified according to the needs of the current study [19]. For instance, questions on protocol, publication bias and heterogeneity were added (Additional file 1: Appendix 3). Quality assessment will be done by two reviewers independently. Any discrepancies will be solved through discussion or involvement of a third reviewer.

\section{Analysis and presentation of the results}

The study selection process will be summarised by using a PRISMA diagram [20]. A narrative analysis of the data gathered via the systematic review will be undertaken. As the study will include reviews focussing on varied health conditions, no sub-group analysis has been planned. Results will be presented in accordance with the Cochrane Handbook for Systematic Reviews of Interventions guidelines [11].

\section{Discussion}

Existing systematic reviews focus on the impact of smoking during pregnancy on particular health conditions. This review aims to draw a broader picture of the current evidence by including systematic reviews that investigated any health outcome associated with smoking whilst pregnant.

\section{Additional file}

Additional file 1: Appendix 1: Sample search strategy from MEDLINE. Appendix 2: Data extraction tool. Appendix 3: Critical appraisal checklist for systematic reviews. (DOCX $23 \mathrm{~kb}$ )

\section{Abbreviations}

CRD: Centre for Reviews and Dissemination; DARE: Database of Abstracts of Reviews of Effects; HMIC: The Healthcare Management Information Consortium; HTA: Health Technology Assessment; NHSEED: NHS Economic Evaluation Database; PRISMA: Preferred Reporting Items for Systematic Review and Meta-Analysis

\section{Acknowledgements}

This review is planned as a part of Tuba Saygın Avşar's PhD study at the University of Birmingham.

\section{Funding}

None.

Availability of data and materials

Not applicable.

Authors' contributions

The search strategy for the database search was developed by all authors through discussion. TSA prepared the first draft for the protocol; HM and LJ provided feedback to improve the protocol. All authors read and approved the final manuscript.

Ethics approval and consent to participate

Not applicable.

Consent for publication

Not applicable.

\section{Competing interests}

The authors declare that they have no competing interests.

\section{Publisher's Note}

Springer Nature remains neutral with regard to jurisdictional claims in published maps and institutional affiliations.

Received: 12 April 2018 Accepted: 28 November 2018

Published online: 19 December 2018

References

1. WHO. Report on the global tobacco epidemic: monitoring tobacco use and prevention policies. Geneva; 2017.

2. OECD. Health at a glance: OECD indicators. Paris: OECD; 2017.

3. NHS Digital. Statistics on smoking, England; NHS; 2017. https://www.gov.uk/ government/statistics/statistics-on-smoking-england-2017. Accessed 11 Dec 2018.

4. Samet, Jonathan M, Yoon, Soon-Young \& WHO Tobacco Free Initiative Women and the tobacco epidemic : challenges for the 21st century / edited by Jonathan M. Samet, Soon-Young Yoon. Geneva: World Health Organization; 2001. http://www.who.int/iris/handle/10665/66799. Accessed 11 Dec 2018.

5. Health and Social Care Information Centre. Statistics on women's smoking status at time of delivery: England; NHS; 2016. https://digital.nhs.uk/dataand-information/publications/statistical/statistics-on-smoking/statistics-onsmoking-england-2017-pas. Accessed 11 Dec 2018

6. Godfrey C, Pickey KE, Parrott S, Mdege N, Eapen D. Estimating the costs to the NHS of smoking in pregnancy: Public Health Reseach Consortium; York; 2010.

7. Marmot M. Social determinants of health inequalities. Lancet. 2005;365(9464): 1099-104.

8. Schaap MM, van Agt HME, Kunst AE. Identification of socioeconomic groups at increased risk for smoking in European countries: looking beyond educational level. Nicotine Tob Res. 2008;10(2):359-69.

9. Banderali G, Martelli A, Landi M, Moretti F, Betti F, Radaelli G, Lassandro C, Verduci E. Short and long term health effects of parental tobacco smoking during pregnancy and lactation: a descriptive review. J Transl Med. 2015;13:327.

10. Bruin JE, Gerstein HC, Holloway AC. Long-term consequences of fetal and neonatal nicotine exposure: a critical review. Toxicol Sci. 2010;116(2):364-74

11. Higgins J, Green S, editors. Cochrane Handbook for Systematic Reviews of Interventions Version 5.1.0. England: Wiley-Blackwell; 2011.

12. Caleyachetty R, Tait CA, Kengne AP, Corvalan C, Uauy R, Echouffo-Tcheugui JB. Tobacco use in pregnant women: analysis of data from demographic and health surveys from 54 low-income and middle-income countries. Lancet Glob Health. 2014:2(9):e513-20. 
13. Barros F, Victora C, Barros A, Santos I, Albernaz E, Matijasevich A, Domingues MR, Sclowitz I, Hallal P, Silveira M, et al. The challenge of reducing neonatal mortality in middle-income countries: findings from three Brazilian birth cohorts in 1982, 1993, and 2004. Lancet. 2005:365(9462):847-54.

14. Finlayson K, Downe S. Why do women not use antenatal services in lowand middle-income countries? A meta-synthesis of qualitative studies. PLoS Med. 2013;10(1). https://doi.org/10.1371/journal.pmed.1001373.

15. World Health Organisation (WHO) and National Cancer Institute (NCI). The economics of tobacco and tobacco control. In: NCI Tobacco Control Monograph Series. Geneva; 2017.

16. Pereira PP, Da Mata FA, Figueiredo AC, de Andrade KR, Pereira MG. Maternal active smoking during pregnancy and low birth weight in the Americas: a systematic review and meta-analysis. Nicotine Tob Res. 2017;19(5):497-505.

17. Zhang D, Cui H, Zhang L, Huang Y, Zhu J, Li X. Is maternal smoking during pregnancy associated with an increased risk of congenital heart defects among offspring? A systematic review and meta-analysis of observational studies. J Matern Fetal Neonatal Med. 2017;30(6):645-57.

18. OECD Members and partners, 2018, [ http://www.oecd.org/about/ membersandpartners/]. Accessed 11 Dec 2018.

19. CRD. CRD's guidance for undertaking reviews in health care: Centre for reviews and dissemination: University of York: York; 2009

20. Moher D, Liberati A, Tetzlaff J, Altman D. Preferred reporting items for systematic reviews and meta analyses: the PRISMA statement. PLoS Med. 2009;6(7). https://doi.org/10.1371/journal.pmed.1000097.

Ready to submit your research? Choose BMC and benefit from:

- fast, convenient online submission

- thorough peer review by experienced researchers in your field

- rapid publication on acceptance

- support for research data, including large and complex data types

- gold Open Access which fosters wider collaboration and increased citations

- maximum visibility for your research: over $100 \mathrm{M}$ website views per year

At BMC, research is always in progress.

Learn more biomedcentral.com/submissions 